\title{
TAXAS DE APARECIMENTO E ALONGAMENTO DO CAPIM-XARAÉS EM DIFERENTES MANEJOS E NÍVEIS DE ADUBAÇÃO, INTERVALOS DE DESFOLHA E ESTAÇÕES ANUAIS ${ }^{1}$
}

Fernando França da Cunha², Carlos Augusto Brasileiro de Alencar², Márcio Mota Ramos ${ }^{4}$ Antônio Carlos Cóser Carlos Eugênio Martins ${ }^{6}$

\section{RESUMO}

Objetivou-se avaliar os efeitos de diferentes manejos e doses de adubação, intervalos de desfolha e estações anuais sobre as características morfogênicas do capim-xaraés. O experimento foi conduzido em esquema de parcelas subsubdivididas, tendo nas parcelas um esquema fatorial 2 × 2, duas estações anuais (inverno e verão) e dois manejos de adubação (convencional e fertirrigação), nas subparcelas quatro intervalos de desfolha (21, 28, 35 e 42 dias) e nas subsubparcelas seis níveis de adubação $\left(0,15,39,64,83\right.$ e 100\% das doses de 700 e $560 \mathrm{~kg}$ de N e $\mathrm{K}_{2} \mathrm{O}$, respectivamente), no delineamento inteiramente casualizado, com quatro repetições. As características morfogênicas foram estudadas por meio das taxas de aparecimento de folhas (TApF) e de alongamento de folhas (TAlF) e colmo (TAlC). Os efeitos proporcionados pelos intervalos de desfolha nas características morfogênicas foram dependentes do manejo, dos níveis de adubação e da estação anual. A estação verão proporcionou maiores médias nas características morfogênicas estudadas. O manejo da adubação (convencional e fertirrigação) não afetou os parâmetros avaliados e o aumento da adubação nitrogenada e potássica proporcionaram acréscimos nas TApF e TAlF.

Palavras-chave: aspersão em linha, Brachiaria brizantha, fertirrigação, morfogênese.

\section{ABSTRACT \\ RATE OF LEAF APPEARANCE AND ELONGATION OF XARAES GRASS UNDER DIFFERENT MANAGEMENT, FERTILIZATION LEVELS, REST PERIOD AND ANNUAL SEASONS}

The objective of is study was to analyze the effects of different management, fertilizer level, rest period and annual seasons on the morphogenetic characteristic of the Xaraes grass. The study was done in a completely randomized split-split-plot design, with four replications, with plots in $2 \times 2$ factorial, two annual seasons (winter and summer) and two fertilizing managements (conventional and fertigation), four rest periods in the split-plots $(21,28,35$ and 42 days) and six fertilizer levels in the split-split-plots $\left(0,15,39,64,83\right.$ and $100 \%$ of the dose of $700 \mathrm{~N}$ and $\left.560 \mathrm{~kg} \mathrm{~K}_{2} \mathrm{O}\right)$. The morphogenesis characteristics were evaluated through the leaf appearance rate (LAR), leaf elongation rate (LER) and stem elongation rate (SER). The effect of the rest period on morphogenesis characteristics was dependent on the management, fertilizer level and the annual seasons. Morphogenesis characteristic means were higher during the summer season. The fertilization management did not affect the evaluated parameters and the increase of the fertilizer rate increased LAR and LER.

Keywords: line source, Brachiaria brizantha, fertigation, morphogenesis.

\section{Recebido para publicação em 12/09/2009. Aprovado em 23/11/2009}

1- Parte da tese de doutorado do primeiro autor, apresentada ao curso de pós-graduação em Engenharia Agrícola, Departamento de Engenharia Agrícola, Universidade Federal de Viçosa.

2- Engenheiro Agrônomo, Doutor em Engenharia Agrícola, DEA/UFV, Viçosa-MG, e-mail: fcunha@vicosa.ufv.br

3- Engenheiro Agrícola, Doutor em Engenharia Agrícola, DEA/UFV, Viçosa-MG, e-mail: brasileiro@yahoo.com.br

4- Engenheiro Agrônomo, Doutor em Engenharia Agrícola, DEA/UFV, Viçosa-MG, e-mail: mmramos@ufv.br

5- Engenheiro Agrônomo, Doutor em Zootecnia, CNPGL/EMBRAPA, Juiz de Fora-MG, e-mail: acoser@cnpgl.embrapa.br

6- Engenheiro Agrônomo, Doutor em Solos, CNPGL/EMBRAPA, Juiz de Fora-MG, e-mail: caeuma@cnpgl.embrapa.br 


\section{INTRODUÇÃO}

Como a produtividade das gramíneas forrageiras está diretamente relacionada à sua capacidade de emitir folhas de meristemas remanescentes após a desfolhação (NABINGER, 1997), estudos básicos de fluxo de tecidos por meio de processos morfogênicos da Brachiaria brizantha cv. Xaraés certamente contribuirão para o estabelecimento de melhor estratégia de manejo, otimizando a produção e utilização dessa forrageira.

A morfogênese vegetalé definida como a dinâmica de geração e expansão da forma da planta no espaço (LEMAIRE \& CHAPMAM, 1996) e, segundo Fagundes et al. (2005), é geneticamente programada, porém influenciada por fatores ambientais como a temperatura, disponibilidade hídrica e de nutrientes, dentre outros.

A morfogênese de uma forrageira durante seu crescimento vegetativo é caracterizada por três fatores: a taxa de aparecimento, a taxa de alongamento e a longevidade das folhas (CHAPMAM \& LEMAIRE, 1993).

O aparecimento de folhas exerce um papel central na morfogênese, devido à sua influência direta sobre cada um dos três componentes estruturais da pastagem (LEMAIRE \& CHAPMAM, 1996).

A taxa de alongamento das folhas parece ser a variável morfogênica que, isoladamente, mais se correlaciona diretamente com a massa seca da forragem (HORST et al., 1978). O alongamento foliar está restrito a uma zona na base da folha em expansão que está protegida pelo conjunto de bainhas das folhas mais velhas ou pseudocolmo, e é dependente do comprimento dessa zona de alongamento e da taxa de alongamento por segmento foliar (SKINNER \& NELSON, 1995).

Objetivou-se, com este trabalho, avaliar os efeitos de diferentes manejos e doses de adubação, intervalos de desfolha e estações anuais sobre as taxas de aparecimento de folhas e de alongamento de folhas e colmo do capim-xaraés.

\section{MATERIAL E MÉTODOS}

Este trabalho foi conduzido de novembro de 2006 a maio de 2008 e realizado na Universidade Vale do Rio Doce, localizado no município de Governador Valadares, MG, sendo as coordenadas geográficas $18^{\circ} 47^{\prime} 30^{\prime \prime}$ de latitude sul e $41^{\circ}$ 59' $04^{\prime}$ 'de longitude oeste e altitude de $223 \mathrm{~m}$.

O solo na área experimental foi classificado como Cambissolo eutrófico, textura média, com a seguinte composição química na camada de 0 a $40 \mathrm{~cm}$ : pH $\left(\mathrm{H}_{2} \mathrm{O}\right)=6,3 ; \mathrm{M} . \mathrm{O} .=2,2 \mathrm{~g} \mathrm{dm}^{-3} ; \mathrm{P}=9,1 \mathrm{mg} \mathrm{dm}^{-3}$; $\mathrm{K}^{+}=179,5 \mathrm{mg} \mathrm{dm}{ }^{-3} ; \mathrm{Ca}^{+2}=3,1 \mathrm{cmol}_{\mathrm{c}} \mathrm{dm}^{-3} ; \mathrm{Mg}^{+2}=$ $0,9 \mathrm{cmol}_{\mathrm{c}} \mathrm{dm}^{-3} ; \mathrm{Al}^{+3}=0,1 \mathrm{cmol}_{\mathrm{c}} \mathrm{dm}^{-3} ; \mathrm{H}+\mathrm{Al}=1,8$ $\mathrm{cmol}_{\mathrm{c}} \mathrm{dm}^{-3}$ e $\mathrm{V}=71 \%$. As correções da acidez e fertilidade foram de acordo com as recomendações da CFSEMG (1999).

A distribuição granulométrica e os resultados das análises físico-hídricas do solo foram as seguintes: argila $=30 \%$; silte $=25 \%$; areia $=45 \%$; capacidade de campo $=29 \%$ b.s.; ponto de murcha $=13 \%$ b.s. e densidade do solo $=1,38 \mathrm{~g} \mathrm{~cm}^{-3}$. A densidade do solo foi determinada pelo método do anel volumétrico e os níveis de umidade do solo na capacidade de campo e no ponto de murcha permanente foram

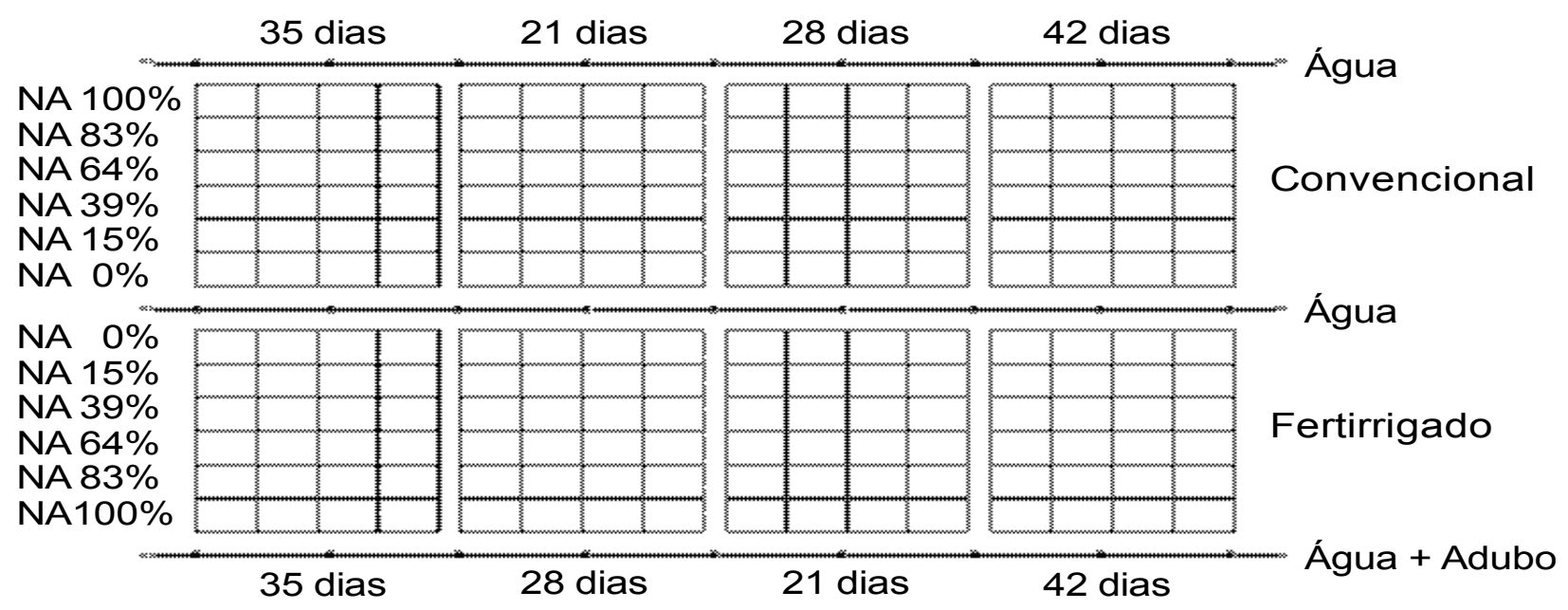

Figura 1. Croqui da área experimental. 
determinados para as tensões de 10 e $1.500 \mathrm{kPa}$, respectivamente. Os valores de retenção de água no solo foram determinados utilizando-se o método da Câmara de Richards (RICHARDS, 1949).

$\mathrm{O}$ experimento foi conduzido em esquema de parcelas sub-subdivididas, tendo nas parcelas um esquema fatorial 2 × 2 (estações anuais e manejos da adubação), nas subparcelas, quatro intervalos de desfolha e nas sub-subparcelas, seis níveis de adubação nitrogenada e potássica, no delineamento inteiramente casualizado com quatro repetições (Figura 1). A dimensão de cada sub-subparcela experimental foi de $3 \mathrm{~m}$ de largura e $3 \mathrm{~m}$ de comprimento, com área de $9 \mathrm{~m}^{2}$.

As estações anuais foram divididas em período seco (inverno) e período chuvoso (verão). Os intervalos de desfolha, ou seja, o intervalo entre um pastejo e outro foram de 21, 28, 35 e 42 dias. Os manejos de adubação consistiram em aplicar a adubação nitrogenada e potássica a lanço (convencional) e por meio da água de irrigação (fertirrigação). No manejo de adubação convencional, a aplicação do adubo era realizada após cada pastejo, de tal maneira que os parcelamentos da adubação nos tratamentos de $21,28,35$ e 42 dias foram de 18 , 13, 11 e 9 aplicações, respectivamente. No manejo de adubação fertirrigado, a aplicação do adubo era realizada a cada evento de irrigação, totalizando 22 aplicações. Os níveis de adubação (DA) foram de $0 \%$ ( $0 \mathrm{~kg}$ de $\mathrm{N}$ e $0 \mathrm{~kg}$ de $\mathrm{K}_{2} \mathrm{O}$ ), $15 \%$ (108 $\mathrm{kg}$ de $\mathrm{N}$ e $86 \mathrm{~kg}$ de $\mathrm{K}_{2} \mathrm{O}$ ), 39\% (272 $\mathrm{kg}$ de $\mathrm{N}$ e $217 \mathrm{~kg}$ de $\mathrm{K}_{2} \mathrm{O}$ ), $64 \%$ (451 kg de $\mathrm{N}$ e $361 \mathrm{~kg}$ de $\left.\mathrm{K}_{2} \mathrm{O}\right), 83 \%(587 \mathrm{~kg}$ de $\mathrm{N}$ e $467 \mathrm{~kg}$ de $\mathrm{K}_{2} \mathrm{O}$ ) e $100 \%$ (700 $\mathrm{kg}$ de $\mathrm{N}$ e 560 $\mathrm{kg} \operatorname{de} \mathrm{K}_{2} \mathrm{O}$ ).

Para diferenciar as doses de adubação no tratamento fertirrigado, utilizou-se a aspersão em linha (HANKS et al., 1976), em que uma linha de aspersores aplicava água juntamente com o adubo e a outra linha fazia apenas a sobreposição com água. O manejo da irrigação foi realizado por meio do monitoramento do potencial de água no solo feita por tensiômetro digital instalado a 15 e $45 \mathrm{~cm}$ de profundidade. As irrigações foram efetuadas quando os tensiômetros instalados a $15 \mathrm{~cm}$ registraram valores de potencial matricial em torno de -60 $\mathrm{kPa}$. A lâmina de irrigação aplicada foi medida com pluviômetros instalados em cada subparcela experimental e calculada por meio da equação 1 .

$\mathrm{L}=\frac{(\mathrm{CC}-\theta)}{10} \mathrm{DZ} \frac{1}{\mathrm{Ea}}$ em que,

$\mathrm{L}=$ lâmina total necessária $(\mathrm{mm}) ; \mathrm{CC}=$ capacidade de campo (\%, b.s.);

$\theta=$ teor atual de água no solo, no potencial matricial de $-60 \mathrm{kPa}(\%$, b.s.);

$\mathrm{D}=$ densidade do solo $\left(\mathrm{g} \mathrm{cm}^{-3}\right) ; \mathrm{Z}=$ profundidade efetiva do sistema radicular $(\mathrm{cm})$; e

$\mathrm{Ea}=$ eficiência de aplicação da água (decimal).

Simultaneamente ao monitoramento da umidade do solo via tensiometria, foram coletados dados meteorológicos diários a partir de uma estação meteorológica automática, instalada dentro da área experimental.

O plantio do capim-xaraés (Brachiaria brizantha cv. Xaraés) foi realizado em 06/11/2006, utilizando-se sementes com valor cultural de $30 \%$. A semeadura foi realizada manualmente em fileiras espaçadas $30 \mathrm{~cm}$, com sementes distribuídas na profundidade média de $2 \mathrm{~cm}$. O corte de uniformização foi realizado em 27/02/2007 à uma altura de $20 \mathrm{~cm}$ da superfície do solo, realizado de forma mecanizada, utilizando-se um trator equipado com roçadeira. No dia 26/04/2007 realizou-se o pastejo de uniformização, de maneira que o resíduo pós-pastejo apresentasse em torno de $15 \%$ de folhas verdes remanescentes (AROEIRA et al., 1999). O mesmo procedimento foi adotado nas demais coletas e nos pastejos seguintes, porém respeitando o intervalo de desfolha de cada tratamento até o término do experimento. Os animais foram utilizados apenas como "ferramenta de corte" após a amostragem de cada gramínea, de maneira que a forragem disponível fosse consumida.

Para avaliação das características morfogênicas, dois perfilhos de cada unidade experimental foram selecionados e marcados com anéis coloridos de fio telefônico após a realização do pastejo simulado. Com auxílio de uma régua, foram efetuadas medições do comprimento das lâminas foliares e do colmo dos perfilhos marcados, três vezes por semana.

O comprimento da lâmina emergente foi medido do seu ápice até a lígula da última folha expandida, enquanto a lâmina expandida teve seu comprimento medido da lígula até seu ápice. O comprimento do colmo foi medido do nível do solo até a lígula da última folha expandida, conforme Gomide \& Gomide (2000).

A partir dos dados obtidos referentes ao estudo 
de crescimento de folhas, foram calculadas as seguintes variáveis:

-Taxa de aparecimento de folhas (TApF, folhas perfilho-1 dia $\left.^{-1}\right)$ - subtraindo o número de folhas surgidas por perfilho em relação às folhas iniciais, pelo número de dias envolvidos;

-Taxa de alongamento de folhas (TAlF, cm perfilho $^{-1}$ dia $^{-1}$ ) - subtraindo os comprimentos iniciais das lâminas de seus comprimentos finais, dividiu-se a diferença obtida pelo número de dias decorridos na avaliação e multiplicados pelo número de perfilhos considerados; e

-Taxa de alongamento de colmo (TAlC, cm perfilho $^{-1}$ dia $^{-1}$ ) - subtraindo os comprimentos iniciais dos colmos de seus comprimentos finais, dividiu-se a diferença obtida pelo número de dias decorridos na avaliação e multiplicados pelo número de perfilhos considerados.

Os dados foram submetidos às análises de variância e de regressão. A comparação de médias foi realizada usando-se o teste de Tukey a $5 \%$ de probabilidade. Para o fator quantitativo, os modelos foram escolhidos com base na significância dos coeficientes de regressão, utilizando-se o teste $\mathrm{t}$ a $10 \%$ de probabilidade, no coeficiente de determinação $\left(\mathrm{R}^{2}=\right.$ S.Q. Regressão/S.Q. Tratamento) e no fenômeno biológico. Para execução das análises estatísticas, foram utilizados os programas estatísticos "SAEG 9.0" (2005), desenvolvido pela Universidade Federal de Viçosa, e o "SIGMA PLOT 10.0". Independentemente da interação entre os fatores ser ou não significativa, optou-se pelo seu desdobramento, devido ao interesse em estudo.

\section{RESULTADOS E DISCUSSÃO}

As médias mensais de radiação solar variaram entre $178 \mathrm{e} 301 \mathrm{~W} \mathrm{~m}^{-2}$ (Figura 2), sendo seus valores mínimos ocorridos nos meses entre abril e setembro e máximos nos meses entre outubro e março, respectivamente. Os valores médios de temperatura do ar durante o período experimental variaram de 18,8 a $26,1^{\circ} \mathrm{C}$ (Figura 2). As temperaturas nunca atingiram valores inferiores à $15^{\circ} \mathrm{C}$, temperatura essa que limita o crescimento e desenvolvimento de gramíneas forrageiras tropicais (COOPER \& TAINTON, 1968).

As taxas de aparecimento de folhas (TApF) do capim-xaraés variaram entre 0,028 a 0,116 folhas perfilho ${ }^{-1}$ dia $^{-1}$ (Quadro 1), valores estes, semelhantes aos obtidos por Silveira (2006) e Martuscello et al. (2005) trabalhando com o mesmo capim, ambos no Município de Viçosa, MG. O efeito proporcionado pelas estações anuais nas TApF foi dependente dos outros fatores estudados. No geral, observou-se maior TApF na estação verão; entretanto, esse efeito foi maior nos tratamentos que receberam maiores níveis de adubação.

Os manejos de adubação não influenciaram as TApF (Quadro 1). Silveira (2006) relata que o efeito de limitações nutricionais e hídricas sobre a TApF não aparece de forma clara na literatura, provavelmente porque, sendo essa característica o parâmetro central da morfogênese das plantas, esta seja a última a ser alterada sob tais condições. Entretanto, o aumento do nível de adubação nitrogenada e potássica proporcionou aumento linear na TApF do capim-xaraés (Figura 3), independente da estação e do manejo da adubação. Todavia, a resposta aos níveis de adubação foi de

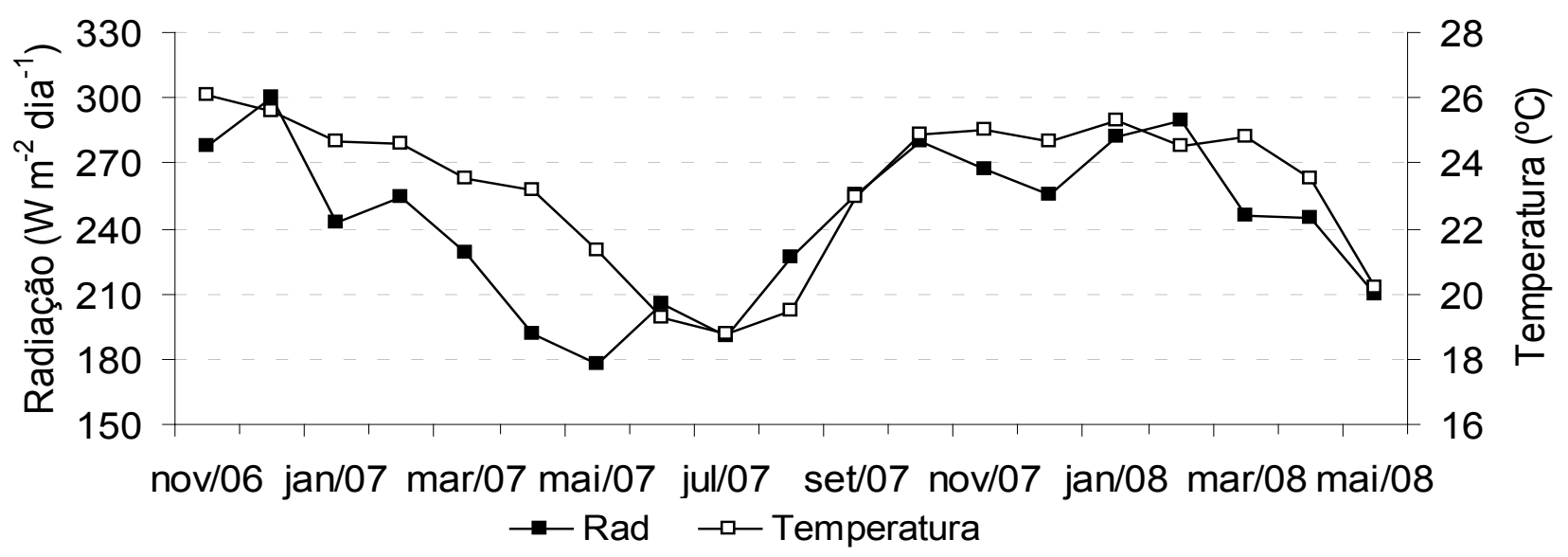

Figura 2. Variação mensal da radiação solar média $\left(\mathrm{W} \mathrm{m}^{-2}\right)$ e da temperatura média $\left({ }^{\circ} \mathrm{C}\right)$, no período de novembro de 2006 a junho de 2008. 
pequena magnitude, como pode ser notado nos seus respectivos coeficientes de regressão (entre $0,0003 \mathrm{e}$ 0,0004). O efeito da nutrição nitrogenada sobre a TApF de gramíneas cespitosas é muito baixo (GASTAL \& LEMAIRE, 1988), enquanto seu efeito sobre a taxa de alongamento da folha (TAlF) é muito importante (GASTAL et al., 1992), levando a grande aumento no tamanho da folha com a elevação do nível de $\mathrm{N}$. Martuscello et al. (2005) avaliando o mesmo capim no Município de Viçosa, MG, também encontraram efeito linear da TApF em resposta ao aumento do nível de adubação nitrogenada. Alexandrino et al. (2005), avaliando o capim-marandu, que é da mesma espécie do capim-xaraés, também encontraram os mesmos resultados no Município de Viçosa, MG.

$\mathrm{O}$ intervalo de desfolha proporcionou efeito quadrático na TApF do capim-xaraés (Figura 3). No tratamento fertirrigado, os valores máximos estimados e obtidos pelas equações foram de 30 e 29 dias, para as estações inverno e verão, respectivamente. No tratamento de manejo de adubação convencional, os máximos estimados obtidos pelas equações foram de 30 dias para ambas estações anuais. A redução das TApF após os 29 a 30 dias possivelmente foi devido ao aumento da altura do pasto ou aumento do comprimento da bainha, o que pode ser explicado pela maior distância a ser percorrida pela folha até a sua emergência. Para gramíneas tropicais, comportamento semelhante foi observado por Barbosa et al. (2002) para o capim-tanzânia sob lotação rotacionada e por Marcelino et al. (2006) para o capim-marandu, em que verificaram que a TApF foi reduzida com o aumento da altura do pasto. Já Skinner \& Nelson (1995), observaram que o maior comprimento da bainha promoveu menores TApF.

As taxas de alongamento de folhas (TAlF) obtidas no presente trabalho (Quadro 2) estão próximas dos valores encontrados por Silveira (2006) no município de Viçosa, MG, para o mesmo capim. Verificou-se em alguns tratamentos, que a TAlF foi maior na estação verão.

Os maiores valores de TAIF verificados nessa estação foram ocasionados por condições ambientais favoráveis, como luz e temperatura (Figura 2). Entretanto, o menor valor de TAIF registrado na estação inverno, segundo Ludlow \& NG (1977), se deve as baixas temperaturas, interrompendo a expansão foliar muito antes que os processos de fotossíntese e divisão de células fossem afetados. Trabalho de Fagundes et al. (2006) com capim-braquiária no Município de Viçosa, MG, corrobora com o presente trabalho.

Quadro 1. Taxas médias de aparecimento de folhas (folhas perfilho-1 dia $^{-1}$ ) nas combinações de intervalos de desfolha (ID), manejos da adubação (MA), níveis de adubação e estações anuais

\begin{tabular}{|c|c|c|c|c|c|c|c|}
\hline \multirow{2}{*}{ ID } & \multirow{2}{*}{ MA } & \multicolumn{2}{|c|}{$0 \%$} & \multicolumn{2}{|c|}{$15 \%$} & \multicolumn{2}{|c|}{$39 \%$} \\
\hline & & Out/Inv & Pri/Ver & Out/Inv & Pri/Ver & Out/Inv & Pri/Ver \\
\hline \multirow{2}{*}{21} & Conv. & $0,041 \mathrm{Aa}$ & $0,054 \mathrm{Aa}$ & $0,054 \mathrm{Aa}$ & $0,061 \mathrm{Aa}$ & $0,058 \mathrm{Aa}$ & $0,058 \mathrm{Aa}$ \\
\hline & Fert. & $0,035 \mathrm{Ab}$ & $0,061 \mathrm{Aa}$ & $0,030 \mathrm{Bb}$ & $0,060 \mathrm{Aa}$ & $0,063 \mathrm{Aa}$ & $0,055 \mathrm{Aa}$ \\
\hline \multirow{2}{*}{28} & Conv. & $0,047 \mathrm{Aa}$ & $0,059 \mathrm{Aa}$ & $0,051 \mathrm{Aa}$ & $0,065 \mathrm{Aa}$ & $0,058 \mathrm{Ab}$ & 0,079 Aa \\
\hline & Fert. & $0,043 \mathrm{Ab}$ & $0,073 \mathrm{Aa}$ & $0,061 \mathrm{Aa}$ & $0,071 \mathrm{Aa}$ & $0,063 \mathrm{Aa}$ & $0,072 \mathrm{Aa}$ \\
\hline \multirow{2}{*}{35} & Conv. & $0,048 \mathrm{Ab}$ & $0,062 \mathrm{Aa}$ & $0,056 \mathrm{Ab}$ & $0,073 \mathrm{Aa}$ & $0,070 \mathrm{Aa}$ & $0,075 \mathrm{Aa}$ \\
\hline & Fert. & $0,052 \mathrm{Ab}$ & $0,074 \mathrm{Aa}$ & $0,055 \mathrm{Aa}$ & $0,068 \mathrm{Aa}$ & $0,061 \mathrm{Ab}$ & $0,079 \mathrm{Aa}$ \\
\hline \multirow{2}{*}{42} & Conv. & $0,028 \mathrm{Aa}$ & $0,038 \mathrm{Aa}$ & $0,045 \mathrm{Aa}$ & $0,040 \mathrm{Aa}$ & $0,047 \mathrm{Aa}$ & $0,040 \mathrm{Aa}$ \\
\hline & Fert. & $0,031 \mathrm{Aa}$ & $0,040 \mathrm{Aa}$ & $0,031 \mathrm{Ba}$ & $0,030 \mathrm{Aa}$ & $0,053 \mathrm{Aa}$ & $0,054 \mathrm{Aa}$ \\
\hline \multirow{2}{*}{ ID } & \multirow{2}{*}{ MA } & \multicolumn{2}{|c|}{$64 \%$} & \multicolumn{2}{|c|}{$83 \%$} & \multicolumn{2}{|c|}{$100 \%$} \\
\hline & & Out/Inv & Pri/Ver & Out/Inv & Pri/Ver & Out/Inv & Pri/Ver \\
\hline \multirow{2}{*}{21} & Conv. & $0,066 \mathrm{Aa}$ & $0,072 \mathrm{Aa}$ & $0,070 \mathrm{Aa}$ & $0,066 \mathrm{Aa}$ & $0,072 \mathrm{Aa}$ & $0,070 \mathrm{Aa}$ \\
\hline & Fert. & $0,078 \mathrm{Aa}$ & $0,083 \mathrm{Aa}$ & $0,081 \mathrm{Aa}$ & $0,078 \mathrm{Aa}$ & $0,083 \mathrm{Aa}$ & $0,081 \mathrm{Aa}$ \\
\hline \multirow{2}{*}{28} & Conv. & $0,055 \mathrm{Ab}$ & $0,079 \mathrm{Ba}$ & $0,068 \mathrm{Ab}$ & $0,055 \mathrm{Ab}$ & $0,079 \mathrm{Ba}$ & $0,068 \mathrm{Ab}$ \\
\hline & Fert. & $0,060 \mathrm{Ab}$ & $0,109 \mathrm{Aa}$ & $0,071 \mathrm{Ab}$ & $0,060 \mathrm{Ab}$ & $0,109 \mathrm{Aa}$ & $0,071 \mathrm{Ab}$ \\
\hline \multirow{2}{*}{35} & Conv. & $0,072 \mathrm{Ab}$ & $0,096 \mathrm{Aa}$ & $0,088 \mathrm{Aa}$ & $0,072 \mathrm{Ab}$ & $0,096 \mathrm{Aa}$ & $0,088 \mathrm{Aa}$ \\
\hline & Fert. & $0,070 \mathrm{Ab}$ & $0,087 \mathrm{Aa}$ & $0,059 \mathrm{Bb}$ & $0,070 \mathrm{Ab}$ & $0,087 \mathrm{Aa}$ & $0,059 \mathrm{Bb}$ \\
\hline \multirow{2}{*}{42} & Conv. & $0,054 \mathrm{Aa}$ & $0,044 \mathrm{Aa}$ & $0,060 \mathrm{Aa}$ & $0,054 \mathrm{Aa}$ & $0,044 \mathrm{Aa}$ & $0,060 \mathrm{Aa}$ \\
\hline & Fert. & $0,051 \mathrm{Aa}$ & $0,047 \mathrm{Aa}$ & $0,059 \mathrm{Aa}$ & $0,051 \mathrm{Aa}$ & $0,047 \mathrm{Aa}$ & $0,059 \mathrm{Aa}$ \\
\hline
\end{tabular}

Médias seguidas de letras maiúsculas diferenciam os manejos de adubação, dentro de cada intervalo de desfolha, e seguidas de letras minúsculas diferenciam as estações anuais, dentro de cada nível de adubação, de acordo com o teste de Tukey $(p<0,05)$. 


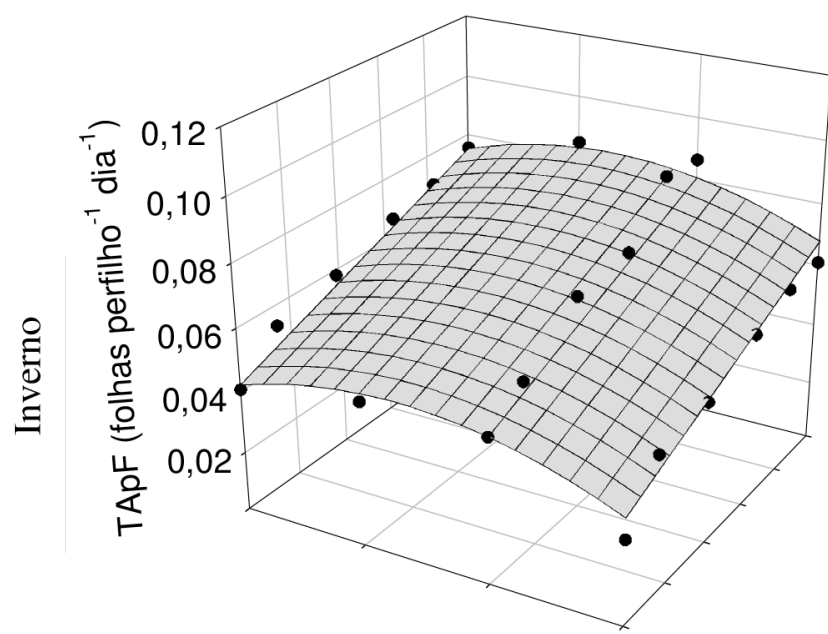

$\mathrm{TApF}=-0,0430+0,0063^{* *} \mathrm{ID}+\ldots$

$\ldots+0,0003^{* *} \mathrm{NA}-0,0001^{* *} \mathrm{ID}^{2}$

$p<0,0001 \quad \mathrm{R}^{2}=0,9080$

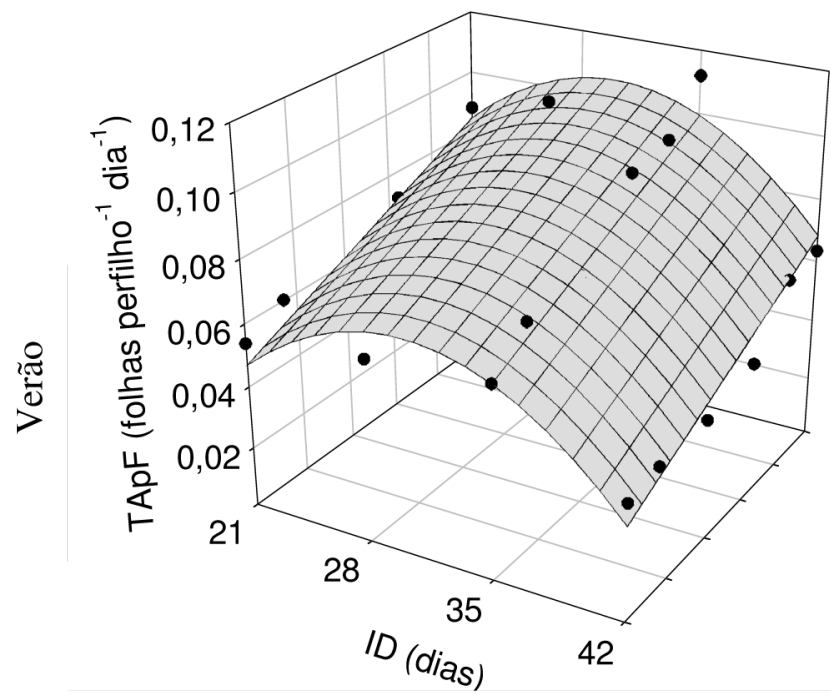

$\mathrm{TApF}=-0,1676+0,0157^{* *} \mathrm{ID}+\ldots$

$\ldots+0,0004^{* *} \mathrm{NA}-0,0003^{* *} \mathrm{ID}^{2}$

$p<0,0001 \quad \mathrm{R}^{2}=0,9484$

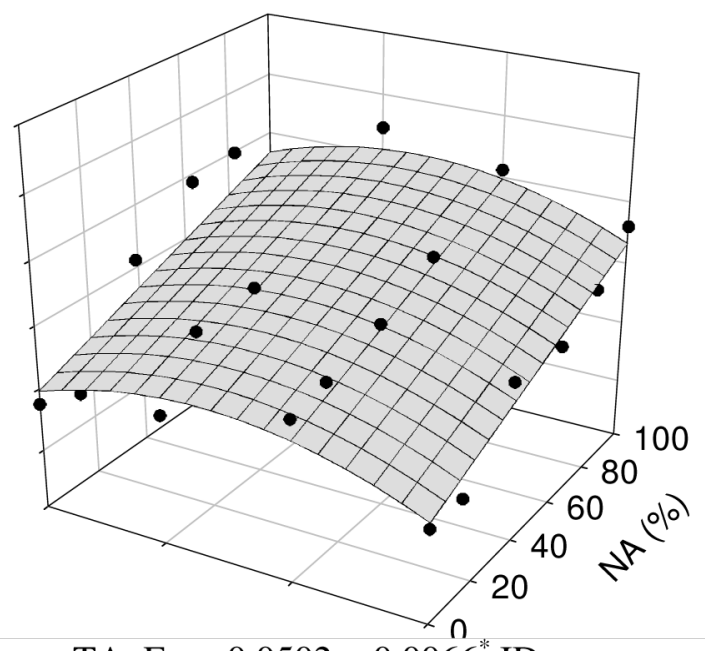

$\mathrm{TApF}=-0,0502+0,0066^{*} \mathrm{ID}+.$.

$$
\ldots+0,0003^{* *} \mathrm{NA}-0,0001^{*} \mathrm{ID}^{2}
$$

$$
p<0,0001 \quad \mathrm{R}^{2}=0,8442
$$

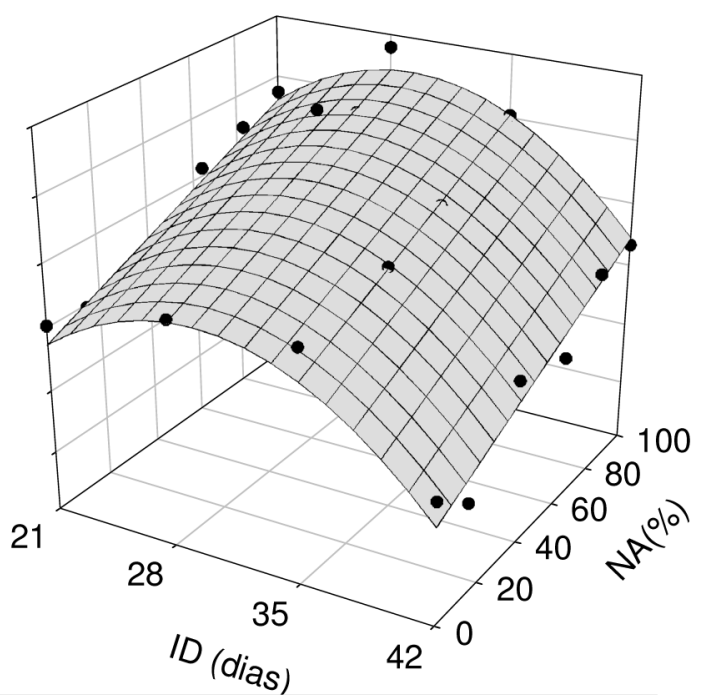

$\mathrm{TApF}=-0,1401+0,0145^{* *} \mathrm{ID}+\ldots$

$\ldots+0,0004^{* *} \mathrm{NA}-0,0002^{* *} \mathrm{ID}^{2}$

$p<0,0001 \quad \mathrm{R}^{2}=0,9432$

$* p<0,05$ e $* * p<0,01$

Figura 3. Estimativa da taxa de aparecimento de folhas (TApF) do capim-xaraés submetido a diferentes manejos de adubação e estações anuais, em função dos intervalos de desfolha (ID) e níveis de adubação (NA). 
Convencional

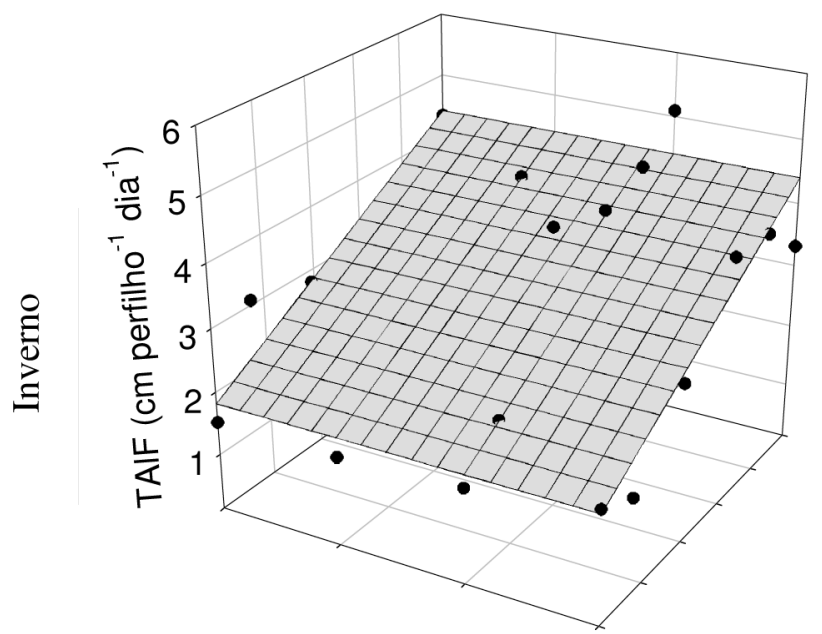

$\mathrm{TAlF}=1,8316+0,0258^{* *} \mathrm{NA}$

$p<0,0001 \quad r^{2}=0,8411$

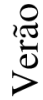

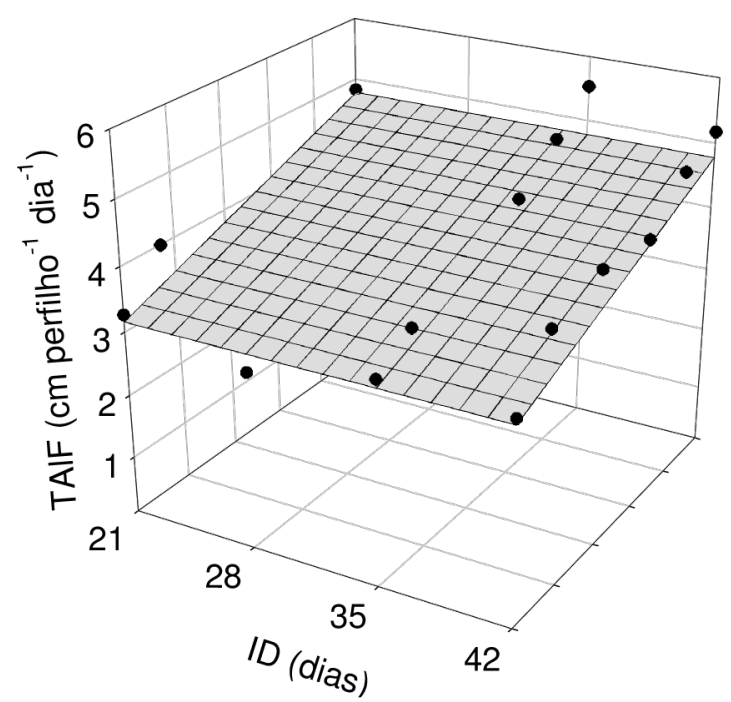

$\mathrm{TAlF}=3,1642+0,0162^{* *} \mathrm{NA}$

$p<0,0001 \quad r^{2}=0,7618$
Fertirrigação

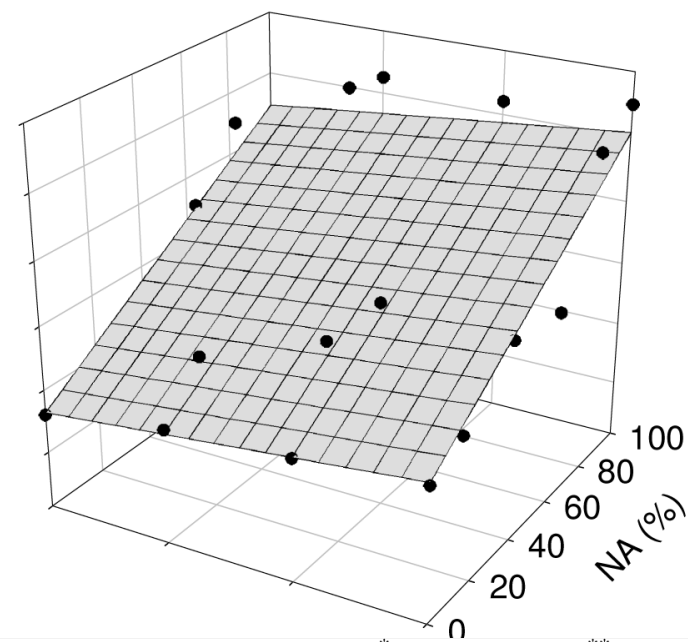

$\mathrm{TAlF}=1,0457+0,0290^{*} \mathrm{ID}+0,0282^{* *} \mathrm{NA}$

$p<0,0001 \quad r^{2}=0,8738$

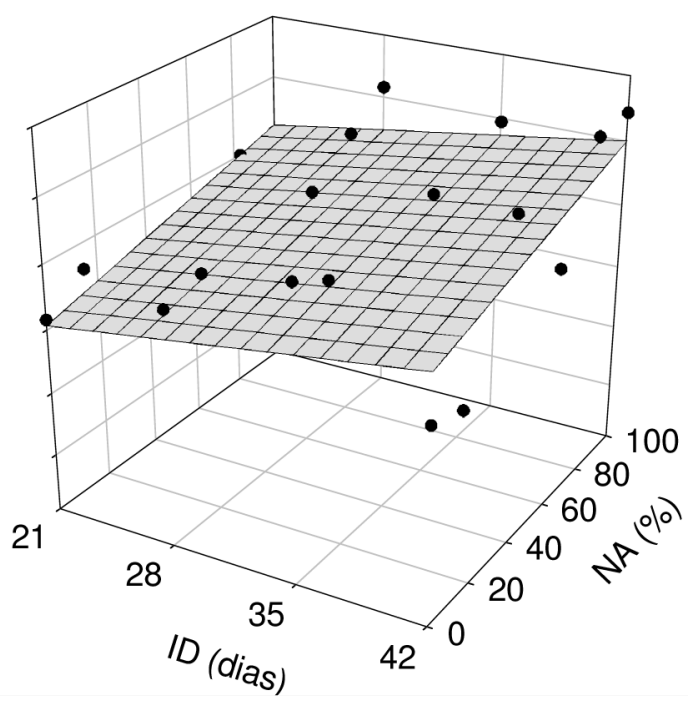

TAIF $=2,2716+0,0383^{*}$ ID $+0,0113^{* *} \mathrm{NA}$

$p<0,0001 \quad r^{2}=0,6236$

$* p<0,05$ e $* * p<0,01$

Figura 4. Estimativa da taxá de alongamento de folhas (TA1F) do cápâtrit-xaraés submetido á diferentes manejos de adubação e estações anuais, em função dos intervalos de desfolha (ID) e níveis de adubação (NA). 


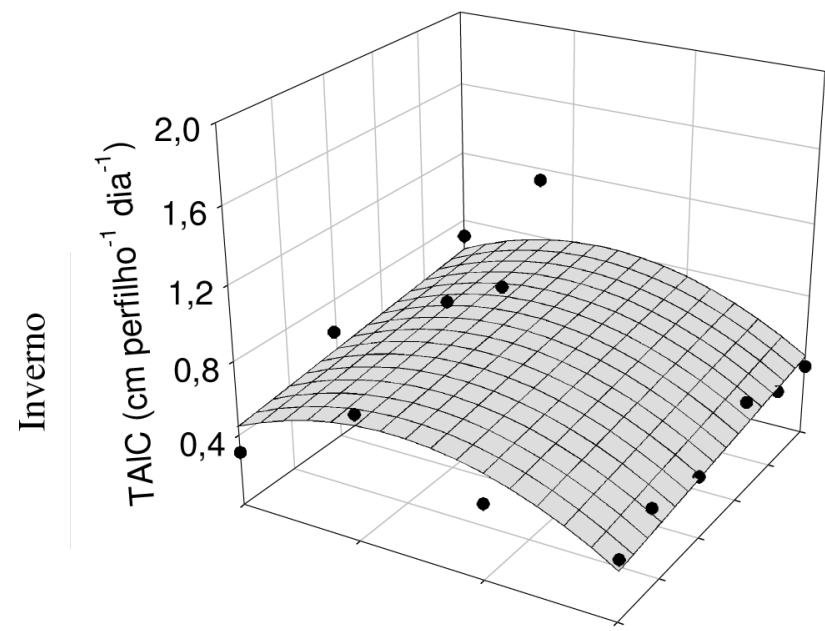

$$
\begin{gathered}
\mathrm{TAlC}=-1,5632+0,1481^{* *} \mathrm{ID}+\ldots \\
\ldots+0,0018^{*} \mathrm{NA}-0,0025^{* *} \mathrm{ID}^{2} \\
p<0,0001 \quad \mathrm{R}^{2}=0,6965
\end{gathered}
$$

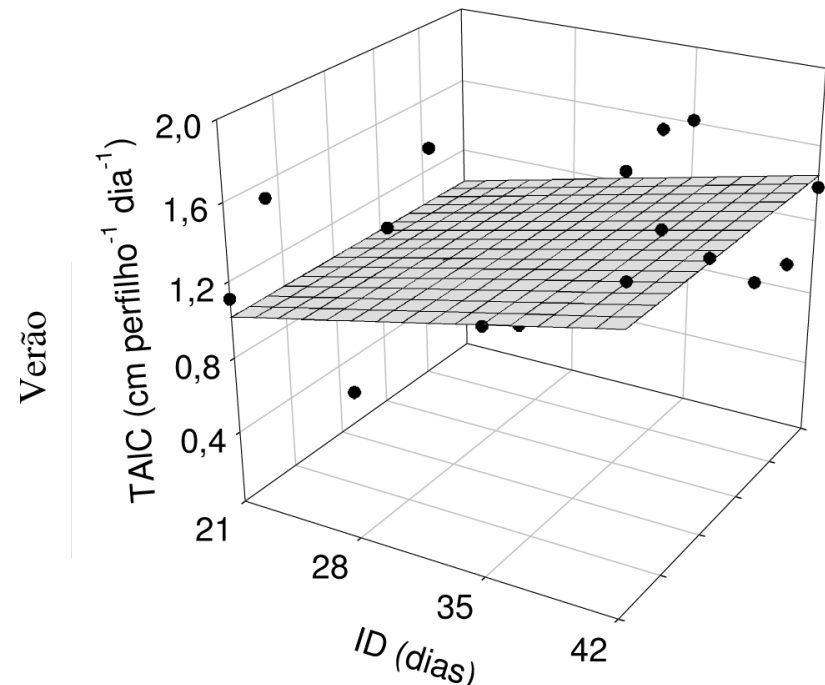

$\mathrm{TAlC}=0,5947+0,0203^{*} \mathrm{ID}$

$$
p<0,0001 \quad r^{2}=0,5493
$$

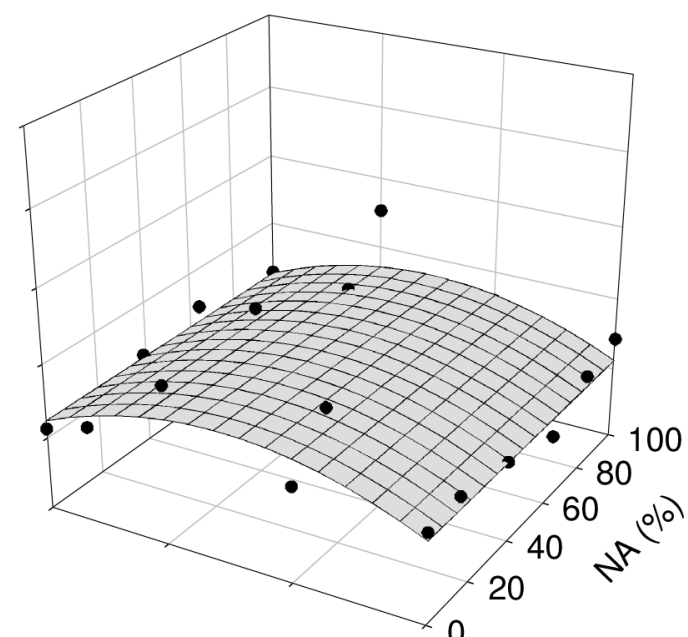

$\mathrm{TAlC}=-1,2824+0,1284^{* *} \mathrm{ID}-0,0021^{* *} \mathrm{ID}^{2}$

$$
p<0,0001 \quad \mathrm{R}^{2}=0,6018
$$

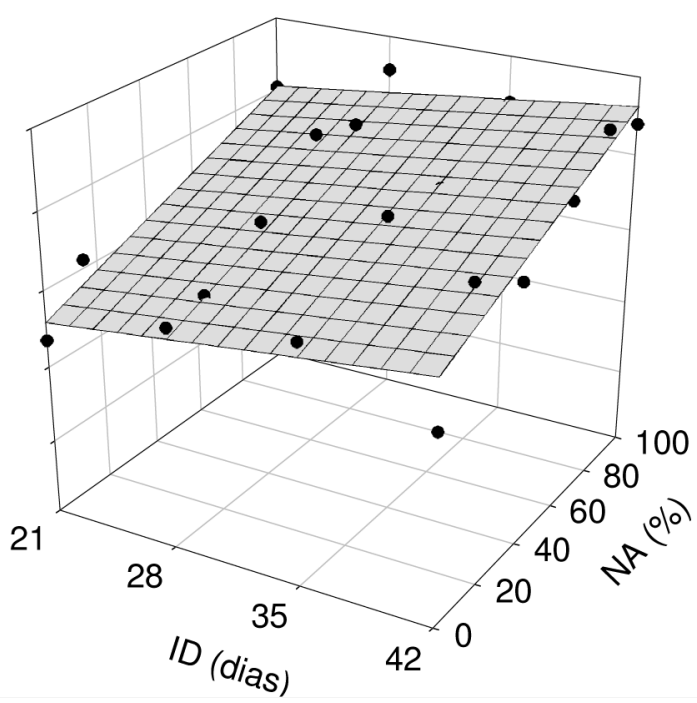

$\mathrm{TAlC}=0,8087+0,0109^{* * *} \mathrm{ID}+0,0058^{* * *} \mathrm{NA}$

$p<0,0001 \quad r^{2}=0,8820$

$* p<0,05 \mathrm{e} * * p<0,01$

Figura 5. Estimativa da taxa de alongamento de colmos (TAlC) do capim-xaraés submetido a diferentes manejos de adubação e estações anuais, em função dos intervalos de desfolha (ID) e níveis de adubação (NA). 
Como observado para as $\mathrm{TApF}$, os diferentes manejos de adubação não conferiram efeito na TAlF do capim-xaraés. Por outro lado, observa-se que independente do manejo da adubação e da estação, o aumento da adubação nitrogenada e potássica proporcionou aumento linear na TAlF do capimxaraés (Figura 4). Martuscello et al. (2005), avaliando o mesmo capim no Município de Viçosa, MG, também encontraram efeito linear da TAlF em resposta ao aumento da dose nitrogenada. Independentemente da magnitude, o efeito da adubação nitrogenada sobre a TAIF pode ser atribuído à grande influência de $\mathrm{N}$ nos processos fisiológicos da planta. Entre os benefícios da aplicação de N, destaca-se o estímulo ao desenvolvimento dos primórdios foliares, o aumento do número de folhas vivas por perfilho, a diminuição do intervalo de tempo para aparecimento de folhas, a redução da senescência foliar e o estímulo ao perfilhamento (PACIULLO et al., 1998). De acordo com Gastal et al. (1992), plantas deficientes em $\mathrm{N}$ apresentam reduções de três a quatro vezes nos valores de TAlF em relação àquelas mantidas sob condições não limitantes.

O aumento do intervalo de desfolha não afetou a TAlF do capim-xaraés quando esse foi adubado de forma convencional, entretanto, com o fertirrigado, verificou-se efeito linear positivo (Figura 4). Marcelino et al. (2006) observaram efeito contrário para o capim-marandu, no Município de Viçosa, MG, em que o aumento do intervalo de desfolha proporcionou menores TAlF.

Esses autores utilizaram intervalos de desfolha de até 56 dias, valor bem acima dos praticados no presente trabalho, sendo uma possível justificativa dos resultados terem sido diferentes.

As taxas de alongamento de colmo (TAlC) variaram de 0,31 até $1,84 \mathrm{~cm}$ perfilho ${ }^{-1}$ dia $^{-1}$ (Quadro 3). Silveira (2006) avaliando o capimxaraés no Município de Viçosa, MG, encontrou TAlC de $0,85 \mathrm{~cm}$ perfilho ${ }^{-1} \mathrm{dia}^{-1}$. Esse autor avaliou o capim-xaraés entre os meses de janeiro e junho, com adubações de $50 \mathrm{~kg} \mathrm{ha}^{-1}$ de $\mathrm{N}$ e $90 \mathrm{~kg} \mathrm{ha}^{-1}$ de $\mathrm{K}_{2} \mathrm{O}$, o que corresponde, aproximadamente, a um nível de 39\% da utilizada no presente trabalho.

No geral, a estação verão proporcionou maiores TAlC do capim-xaraés (Quadro 3). Os maiores valores de TAIC verificados na estação verão também se devem às condições ambientais favoráveis, como luz e temperatura (Figura 2). Esses resultados corroboram aos encontrados por Fagundes et al. (2006) para o capim-marandu, que é da mesma espécie estudada no presente trabalho.

Quadro 2. Taxas médias de alongamento de folhas $\left(\mathrm{cm}\right.$ perfilho-1 dia $\left.^{-1}\right)$ nas combinações de intervalos de desfolha (ID), manejos da adubação (MA), níveis de adubação e estações anuais

\begin{tabular}{|c|c|c|c|c|c|c|c|}
\hline \multirow{2}{*}{ ID } & \multirow{2}{*}{ MA } & \multicolumn{2}{|c|}{$0 \%$} & \multicolumn{2}{|c|}{$15 \%$} & \multicolumn{2}{|c|}{$39 \%$} \\
\hline & & Out/Inv & Pri/Ver & Out/Inv & Pri/Ver & Out/Inv & Pri/Ver \\
\hline \multirow{2}{*}{21} & Conv. & $1,53 \mathrm{Ab}$ & $3,28 \mathrm{Aa}$ & $3,09 \mathrm{Aa}$ & $1,53 \mathrm{Ab}$ & $3,28 \mathrm{Aa}$ & $3,09 \mathrm{Aa}$ \\
\hline & Fert. & $1,62 \mathrm{Ab}$ & $3,17 \mathrm{Aa}$ & $1,84 \mathrm{Ab}$ & $1,62 \mathrm{Ab}$ & 3,17 Aa & $1,84 \mathrm{Ab}$ \\
\hline \multirow{2}{*}{28} & Conv. & $1,53 \mathrm{Aa}$ & $2,89 \mathrm{Aa}$ & $1,82 \mathrm{Aa}$ & $1,53 \mathrm{Aa}$ & $2,89 \mathrm{Aa}$ & $1,82 \mathrm{Aa}$ \\
\hline & Fert. & $1,93 \mathrm{Ab}$ & $3,80 \mathrm{Aa}$ & $2,66 \mathrm{Aa}$ & $1,93 \mathrm{Ab}$ & $3,80 \mathrm{Aa}$ & $2,66 \mathrm{Aa}$ \\
\hline \multirow{2}{*}{35} & Conv. & $1,63 \mathrm{Ab}$ & $3,30 \mathrm{Aa}$ & $2,23 \mathrm{Ab}$ & $1,63 \mathrm{Ab}$ & $3,30 \mathrm{Aa}$ & $2,23 \mathrm{Ab}$ \\
\hline & Fert. & $2,05 \mathrm{Ab}$ & $4,66 \mathrm{Aa}$ & 3,39 Aa & $2,05 \mathrm{Ab}$ & 4,66 Aa & $3,39 \mathrm{Aa}$ \\
\hline \multirow{2}{*}{42} & Conv. & $1,91 \mathrm{Aa}$ & $3,26 \mathrm{Aa}$ & $1,61 \mathrm{Ab}$ & $1,91 \mathrm{Aa}$ & $3,26 \mathrm{Aa}$ & $1,61 \mathrm{Ab}$ \\
\hline & Fert. & $2,23 \mathrm{Aa}$ & $3,14 \mathrm{Aa}$ & $2,52 \mathrm{Aa}$ & $2,23 \mathrm{Aa}$ & $3,14 \mathrm{Aa}$ & $2,52 \mathrm{Aa}$ \\
\hline \multirow[b]{2}{*}{ ID } & \multirow{2}{*}{ MA } & \multicolumn{2}{|c|}{$64 \%$} & \multicolumn{2}{|c|}{$83 \%$} & \multicolumn{2}{|c|}{$100 \%$} \\
\hline & & Out/Inv & Pri/Ver & Out/Inv & Pri/Ver & Out/Inv & Pri/Ver \\
\hline \multirow{2}{*}{21} & Conv. & $3,02 \mathrm{Aa}$ & $3,44 \mathrm{Aa}$ & $3,61 \mathrm{Aa}$ & $3,02 \mathrm{Aa}$ & $3,44 \mathrm{Aa}$ & $3,61 \mathrm{Aa}$ \\
\hline & Fert. & $3,50 \mathrm{Aa}$ & $2,74 \mathrm{Aa}$ & 4,49 Aa & $3,50 \mathrm{Aa}$ & $2,74 \mathrm{Aa}$ & $4,49 \mathrm{Aa}$ \\
\hline \multirow{2}{*}{28} & Conv. & $2,61 \mathrm{Aa}$ & $3,27 \mathrm{Aa}$ & $4,01 \mathrm{Aa}$ & $2,61 \mathrm{Aa}$ & $3,27 \mathrm{Aa}$ & $4,01 \mathrm{Aa}$ \\
\hline & Fert. & $3,43 \mathrm{Aa}$ & $4,16 \mathrm{Aa}$ & $5,40 \mathrm{Aa}$ & $3,43 \mathrm{Aa}$ & $4,16 \mathrm{Aa}$ & $5,40 \mathrm{Aa}$ \\
\hline \multirow{2}{*}{35} & Conv. & $4,25 \mathrm{Aa}$ & $4,48 \mathrm{Aa}$ & $4,55 \mathrm{Aa}$ & $4,25 \mathrm{Aa}$ & $4,48 \mathrm{Aa}$ & $4,55 \mathrm{Aa}$ \\
\hline & Fert. & $2,72 \mathrm{Bb}$ & 4,53 Aa & $3,68 \mathrm{Aa}$ & $2,72 \mathrm{Bb}$ & $4,53 \mathrm{Aa}$ & $3,68 \mathrm{Aa}$ \\
\hline \multirow{2}{*}{42} & Conv. & $3,96 \mathrm{Aa}$ & $4,28 \mathrm{Aa}$ & $3,90 \mathrm{Aa}$ & $3,96 \mathrm{Aa}$ & $4,28 \mathrm{Aa}$ & $3,90 \mathrm{Aa}$ \\
\hline & Fert. & $3,08 \mathrm{Aa}$ & $3,81 \mathrm{Aa}$ & $5,10 \mathrm{Aa}$ & $3,08 \mathrm{Aa}$ & $3,81 \mathrm{Aa}$ & $5,10 \mathrm{Aa}$ \\
\hline
\end{tabular}

Médias seguidas de letras maiúsculas diferenciam os manejos de adubação, dentro de cada intervalo de desfolha, e seguidas de letras minúsculas diferenciam as estações anuais, dentro de cada nível de adubação, de acordo com o teste de Tukey $(p<0,05)$. 
Em plantas forrageiras tropicais, a fração colmo, importante para o crescimento, interfere na estrutura do dossel e nos processos de competição por luz. Pinto et al. (2001) relatam que aproximadamente 60 a $75 \%$ do crescimento de planta é proveniente do alongamento de colmo, e não apenas da expansão de folhas.

Não foi verificado efeito dos manejos de adubação na TAlC do capim-xaraés. Quanto ao efeito dos níveis de adubação, verifica-se resposta linear positiva apenas no tratamento de manejo de adubação convencional na estação inverno e no tratamento fertirrigado na estação verão (Figura 5). Todavia, a resposta aos níveis de adubação foi de pequena magnitude, como pode ser notado nos seus respectivos coeficientes de regressão. Esse resultado corrobora com os obtidos por Fagundes et al. (2006) para o capim-marandu no Município de Viçosa, MG. Os autores creditaram a não resposta aos níveis de adubação, ao efeito do parcelamento do nitrogênio em pastagem mantida em mesma altura, considerando-se, o ano todo.

O intervalo de desfolha proporcionou efeito linear positivo na estação verão, ou seja, o aumento do intervalo entre pastejo proporcionou aumento na TAlC do capim-xaraés (Figura 5). Já na estação inverno, verificou-se que os intervalos de desfolha proporcionaram efeito quadrático na TAlC do capim-xaraés, em que os valores máximos estimados e obtidos pelas equações foram de 30 e 31 dias, para os tratamentos de manejo de adubação convencional e fertirrigado, respectivamente. Cândido et al. (2005) verificaram, no capim-mombaça sob pastejo rotacionado, que o prolongamento do intervalo de desfolha acarretou em maior altura e maior massa seca de forragem verde por ciclo de pastejo, porém com proporção crescente de colmos, levando a uma acentuada redução na relação lâmina:colmo. Assim, embora o desenvolvimento de colmo favoreça o aumento da produção de matéria seca por ciclo de pastejo, há aspectos negativos e que devem ser levados em consideração, como o menor número de ciclos de pastejo ao longo do ano, menor aproveitamento e menor valor nutritivo da forragem produzida (SANTOS et al., 2006).

\section{CONCLUSÕES}

Diante dos resultados, concluiu-se que:
- A estação verão proporciona maiores médias nas taxas de aparecimento de folhas e de alongamento de folhas e colmo do capim-xaraés;

- O manejo da adubação não afeta as características morfogênicas estudadas e o aumento da adubação nitrogenada e potássica proporcionam acréscimos nas taxas de aparecimento e alongamento de folhas;

- O capim-xaraés apresenta maiores taxas de aparecimento de folhas nos intervalos de desfolha entre 29 e 30 dias. O aumento do intervalo de desfolha proporciona aumento na taxa de alongamento de folhas quando o capim-xaraés é fertirrigado. Na estação verão, o intervalo de desfolha proporciona aumento linear na taxa de alongamento de colmo, e na estação inverno, verificam-se maiores taxas no intervalo de desfolha entre 30 e 31 dias.

\section{AGRADECIMENTOS}

Ao Conselho Nacional de Desenvolvimento Científico e Tecnológico (CNPq) pela concessão da bolsa de estudos.

\section{REFERÊNCIAS BIBLIOGRÁFICAS}

ALEXANDRINO, E.; NASCIMENTO Jr., D.; REGAZZI, A.J.; MOSQUIM, P.R.; ROCHA, F.C.; SOUZA, D.P. Características morfogênicas e estruturais da Brachiaria brizantha cv. Marandu submetida a diferentes doses de nitrogênio e freqüências de cortes. Acta Scientiarum Agronomy, Maringá, v.27, n.1, p.17-24, 2005.

AROEIRA, L.J.M.; LOPES, F.C.F.; DERESZ, F.; VERNEQUE, R.S.; DAYRELL, M.S.; MATOS, L.L.; MALDONADO VASQUEZ, H.; VITTORI, A. Pasture availability and dry matter intake of lactating crossbred cows grazing elephant grass (Pennisetum purpureum, Schum). Animal Feed Science and Technology, Amsterdam, v.78, n.2, p.313-324, 1999.

BARBOSA, R.A.; NASCIMENTO Jr., D.; EUCLIDES, V.P.B.; REGAZZI, A.J.; FONSECA, D.M. Características morfogênicas e acúmulo de forragem do capim-tanzânia (Panicum maximum Jacq. cv. Tanzânia) em dois resíduos forrageiros póspastejo. Revista Brasileira de Zootecnia, Viçosa, 
v.31, n.2, p.583-593, 2002.

CÂNDIDO, M.J.D.; GOMIDE, C.A.M.; ALEXANDRINO, E.; GOMIDE, J.A.; PEREIRA, W.E. Morfofisiologia do dossel de Panicum maximum cv. Mombaça sob lotação intermitente com três períodos de descanso. Revista Brasileira de Zootecnia, Viçosa, v.34, n.2, p.406-415, 2005.

CFSEMG - Comissão de Fertilidade do Solo do Estado de Minas Gerais. Recomendações para o uso de corretivos e fertilizantes em Minas Gerais: $5^{a}$ aproximação. 20.ed. Viçosa: Editora UFV, 1999. 359 p.

CHAPMAN, D.F.; LEMAIRE, G. Morphogenetic and structural determinants of plant regrowth after defoliation. In: INTERNACIONAL GRASSLAND CONGRESS, 17., 1993, Palmerston North. Proceedings... Palmerston North: New Zealand Grassland Association, 1993. p.95-104.

COOPER, J.P.; TAINTON, N.M. Light and temperature requirements for the growth of tropical and temperate grasses. Review article. Herbage Abstracts, Hurley, v.38, n.3, p.167-176, 1968.

FAGUNDES, J.L.; FONSECA, D.M.; GOMIDE, J.A.; NASCIMENTO Jr., D.; VITOR, C.M.T.; MORAIS, R.V.; MISTURA, C.; REIS, G.C.; MARTUSCELLO, J.A. Acúmulo de forragem em pastos de Brachiaria decumbens adubados com nitrogênio. Pesquisa Agropecuária Brasileira, Brasília, v.40, n.4, p.397-403, 2005.

FAGUNDES, J.L.; FONSECA, D.M.; MISTURA, C.; MORAIS, R.V.; VITOR, C.M.T.; GOMIDE, J.A.; NASCIMENTO Jr., D.; CASAGRANDE, D.R.; COSTA, L.T. Características morfogênicas e estruturais do capim-braquiária em pastagem adubada com nitrogênio avaliadas nas quatro estações do ano. Revista Brasileira de Zootecnia, Viçosa, v.35, n.1, p.21-29, 2006.

GASTAL, F.; BELANGER, G.; LEMAIRE, G. A model of leaf extension rate of tall fescue in response to nitrogen and temperature. Annals of Botany, London, v.70, n.2, p.437-442, 1992.

GASTAL, F.; LEMAIRE, G. Study of a tall fescue sward growth under nitrogen deficiency conditions.
In: GENERAL MEETING OF THE EUROPEAN GRASSLAND FEDERATION, 12., 1988, Dublin. Proceedings... Dublin: Ireland, 1988. p.323-327.

GOMIDE, C.A.M.; GOMIDE, J.A. Morfogênese de cultivares de Panicum maximum Jacq. Revista Brasileira de Zootecnia, Viçosa, v.29, n.2, p.341348, 2000.

HANKS, R.J.; KELLER, J.; RASMUSSEN, V.P.; WILSON, G.D. Line source sprinkler for continuous variable irrigation-crop production studies. Soil Science Society of America Journal, Madison, v.40, n.3, p.426-429, 1976.

HORST, G.L.; NELSON, C.J.; ASAY, K.H. Relationship of leaf elongation to forage yield of tall fescue genotypes. Crop Science, Madison, v.18, n.5, p.715-719, 1978.

LEMAIRE, G.; CHAPMAN, D.F. Tissue flows in grazed plant communities. In: HODGSON, J.; ILLIUS, A.W. (eds.). The ecology and management of grazing systems. Wallingford: UK/CAB International, 1996, p.3-36.

LUDLOW, M.M.; NG, T.T. Leaf elongation rate in Panicum maximum var. trichoglume following removal of water stress. Australian Journal of Plant Physiology, Melbourne, v.4, n.2, p.263-272, 1977.

MARCELINO, K.R.A.; NASCIMENTO Jr., D.; SILVA, S.C.; EUCLIDES, V.P.B.; FONSECA, D.M. Características morfogênicas e estruturais e produção de forragem do capim-marandu submetido a intensidades e freqüências de desfolhação. Revista Brasileira de Zootecnia, Viçosa, v.35, n.6, p.22432252, 2006.

MARTUSCELLO, J.A.; FONSECA, D.M.; NASCIMENTO Jr., D.; SANTOS, P.M.; RIBEIRO Jr., J.I.; CUNHA, D.N.F.V.; MOREIRA, L.M. Características morfogênicas e estruturais do capim-xaraés submetido à adubação nitrogenada e desfolhação. Revista Brasileira de Zootecnia, Viçosa, v.34, n.5, p.1475-1482, 2005.

NABINGER, C. Eficiência de uso de pastagens: disponibilidade e perdas de forragem. In: SIMPÓSIO SOBRE MANEJO DA PASTAGEM, 14., 1997, 
Piracicaba. Anais... Piracicaba: ESALQ, 1997. p.231-251.

PACIULLO, D.S.C.; GOMIDE, J.A.; RIBEIRO, K.G. Adubação nitrogenada do capim-elefante cv. Mott. 1. Rendimento forrageiro e características morfofisiológicas ao atingir 80 e $120 \mathrm{~cm}$ de altura. Revista Brasileira de Zootecnia, Viçosa, v.27, n.6, p.1069-1075, 1998.

PINTO, L.F.M.; SILVA, S.C.; SBRISSIA, A.F.; CARVALHO, C.A.B.; CARNEVALLI, R.A.; FAGUNDES, J.L.; PEDREIRA, C.G.S. Dinâmica do acúmulo de matéria seca em pastagens de Tifton 85 sob pastejo. Scientia Agricola, Piracicaba, v.58, n.3, p.439-447, 2001.

RICHARDS, L.A. Methods of measuring soil moisture tension. Soil Science of American

Journal, Baltimore, v.68, n.1, p.95-112, 1949.

SANTOS, P.M.; CORSI, M.; PEDREIRA, C.G.S.; LIMA, C.G. Tiller cohort development and digestibility in Tanzania guinea grass (Panicum maximum $\mathrm{cv}$. Tanzania) under three levels of grazing intensity. Tropical Grasslands, Austrália, v.40, n.2, p.84-93, 2006.

SILVEIRA, M.C.T. Caracterização morfogênica de oito cultivares do gênero Brachiaria e dois do gênero Panicum. Viçosa: UFV, 2006. 91p. Dissertação Mestrado.

SKINNER, R.H.; NELSON, C.J. Elongation of the grass leaf and its relationship to the phyllochron. Crop Science, Madison, v.35, n.1, p.4-10, 1995.

ANEXOS:

Anexo 1. Resumo da análise de variância das taxas de aparecimento de folhas (TApF), e alongamento de folha (TAlF) e colmos (TAlC)

\begin{tabular}{|c|c|c|c|c|}
\hline \multirow{2}{*}{ Fonte de Variação } & \multirow{2}{*}{$\begin{array}{l}\text { Grau de } \\
\text { Liberdade }\end{array}$} & \multicolumn{3}{|c|}{ Quadrado Médio } \\
\hline & & TApF & TAlF & TAlC \\
\hline EA & 1 & $1,65 \mathrm{E}-02 * *$ & $5,54 \mathrm{E}+01 * *$ & $5,58 \mathrm{E}+01 * *$ \\
\hline MA & 1 & $7,24 \mathrm{E}-05$ NS & $2,37 \mathrm{E}+00 *$ & $1,07 \mathrm{E}+00 * *$ \\
\hline EA x MA & 1 & $6,48 \mathrm{E}-04 * *$ & $7,82 \mathrm{E}-011^{\mathrm{NS}}$ & $1,10 \mathrm{E}+00 * *$ \\
\hline Resíduo (a) & 12 & 4,81E-05 & 5,11E-01 & $3,52 \mathrm{E}-02$ \\
\hline ID & 3 & $1,40 \mathrm{E}-02 * *$ & $6,58 \mathrm{E}+00 * *$ & $7,23 \mathrm{E}-01 * *$ \\
\hline ID x EA & 3 & $2,39 \mathrm{E}-03 * *$ & $1,13 \mathrm{E}+00^{\mathrm{NS}}$ & $1,75 \mathrm{E}+00 * *$ \\
\hline ID x MA & 3 & $4,98 \mathrm{E}-04 * *$ & $5,83 \mathrm{E}+00 * *$ & $1,52 \mathrm{E}-01 * *$ \\
\hline ID $x$ EA x MA & 3 & $6,82 \mathrm{E}-05$ NS & $1,34 \mathrm{E}+00 *$ & $4,05 \mathrm{E}-01 * *$ \\
\hline Resíduo (b) & 36 & 8,54E-05 & 4,29E-01 & $3,24 \mathrm{E}-02$ \\
\hline NA & 5 & $1,23 \mathrm{E}-02 * *$ & $4,26 \mathrm{E}+01 * *$ & $3,45 \mathrm{E}-01 * *$ \\
\hline NA x EA & 5 & $3,67 \mathrm{E}-04 * *$ & $5,20 \mathrm{E}+00 * *$ & $1,35 \mathrm{E}-01 *$ \\
\hline NA x MA & 5 & $2,24 \mathrm{E}-04 * *$ & $7,00 \mathrm{E}-01^{\mathrm{NS}}$ & $3,33 \mathrm{E}-01 * *$ \\
\hline NA x ID & 15 & $1,74 \mathrm{E}-04 * *$ & $1,22 \mathrm{E}+00 * *$ & $5,86 \mathrm{E}-02$ NS \\
\hline NA $x$ EA x MA & 5 & $3,17 \mathrm{E}-05$ NS & $1,04 \mathrm{E}+00 \mathrm{Ns}$ & $5,83 \mathrm{E}-01 * *$ \\
\hline NA x EA x ID & 15 & $2,33 \mathrm{E}-04 * *$ & $1,20 \mathrm{E}+00 * *$ & $1,50 \mathrm{E}-01 * *$ \\
\hline NA x MA x ID & 15 & $2,95 \mathrm{E}-04 * *$ & $1,82 \mathrm{E}+00 * *$ & $1,58 \mathrm{E}-01 * *$ \\
\hline NA $x$ EA x MA $x$ ID & 15 & $1,74 \mathrm{E}-04 * *$ & 6,92E-01 Ns & $1,18 \mathrm{E}-01 * *$ \\
\hline Resíduo (c) & 240 & $4,67 \mathrm{E}-05$ & $5,28 \mathrm{E}-01$ & $4,88 \mathrm{E}-02$ \\
\hline Total & 383 & $4,22 \mathrm{E}-04$ & $1,52 \mathrm{E}+00$ & $2,48 \mathrm{E}-01$ \\
\hline CV (\%) Parcela & & 10,51 & 19,68 & 19,55 \\
\hline CV (\%) Subparcela & & 14,01 & 18,03 & 18,75 \\
\hline CV (\%) Subsubparcela & & 10,36 & 20,01 & 23,03 \\
\hline
\end{tabular}

